\title{
Validation of molecular markers linked with QTLs for heat and drought stress tolerance in wheat
}

Garima Singroha, Shefali, Satish Kumar, Sanjay Kumar Singh, Gyanendra Singh, Gyanendra Pratap Singh and Pradeep Sharma*

ICAR-Indian Institute of Wheat and Barley Research, Karnal-132 001

\section{Article history}

Received:12 Nov., 2020

Revised : 9 Dec., 2020

Accepted: 16 Dec., 2020

\section{Citation}

Singroha G, Shefali, S Kumar, SK Singh, G Singh, GP Singh and P Sharma 2020. Validation of molecular markers linked with QTLs for heat and drought stress tolerance in wheat. Journal of Cereal Research 12(3): 309-316. http:// doi.org/10.25174/2582-2675/2020/107204

\section{*Corresponding author}

Email: Pradeep.sharma@icar.gov.in

(C) Society for Advancement of Wheat and Barley Research

\begin{abstract}
Global climatic changes affect the production and productivity of wheat around the world. Increasing heat and drought are the most important abiotic stress factors that hinder productivity. To produce sufficient wheat there is urgent need to develop heat and drought tolerant wheat cultivars; therefore, identification of genetic diversity present among available wheat genotypes using SSRs markers is of prime importance. The allelic variation present among wheat genotypes can be deployed in breeding heat and drought tolerant cultivars. A set of 36 wheat genotypes was evaluated for evaluating genetic diversity for heat and drought tolerance among wheat genotypes using already reported SSR markers. A total of 24 SSR markers were analysed and out of them 19 were found polymorphic. Using SSR markers data cluster analysis was carried out to classify the wheat cultivars for genetic variation in heat tolerance. The dendrogram constructed using SSR markers data assigned the 36 wheat cultivars into three broad clusters. The polymorphic SSRs thus identified could be used to evaluate genetic diversity present among wheat genotypes and the wheat cultivars thus identified could be exploited in wheat breeding programs.
\end{abstract}

Keywords: Heat, drought, wheat, SSR markers, polymorphism, cluster analysis

\section{Introduction}

Wheat belonging to the Poaceae family is the most cultivated cereal crop and is the largest contributor in world grain production. FAO $(2018,2019)$ predicts an additional requirement of 198 million tonnes of wheat by 2050 . In order to achieve the required levels, wheat production needs to be increased sufficiently in developing countries (Kumar et al. 2019).However, there are certain environmental factors that affect plants growth and development and impact wheat yields. Increasing global temperature intensifies drought stress and both are the most important limiting factor in agriculture affecting productivity. Parts of West and South Asia, North Africa and sub Saharan Africa faces drought and high temperatures during anthesis and early grain filling stage (Izanloo et al., 2008; Ortiz et al., 2008; Schillinger et al., 2008; Talukder et al., 2014; Gbegbelegbe et al., 2016; Toreti et al., 2019). Drought and heat stress at reproductive stage significantly reduces wheat yields by reducing spikelet fertility, grain number, and single grain weight (Senapati et al., 2019). Increased temperature causes reduction in developmental stage duration thus resulting in lower biomass accumulation (Lobell et al., 2012; Chand et al., 2014).

Wheat is very susceptible to heat and drought at reproductive and grain filling stage (Alexander et al., 2006; Gaffen and Ross 1998; Hennessy et al., 2008). Heat and drought stress during the reproductive phase is more pronounced than during the vegetative phase due to the direct effect on grain number and dry weight (Wollenweber et al., 2013).Asseng et al. (2015) estimated that every $1^{\circ} \mathrm{C}$ rise in temperature may affect global 
wheat production by $6 \%$. Under abiotic stress conditions cellular structures are more prone to damage affecting various metabolic pathways, especially those relating to membrane thermo stability, photosynthesis and starch synthesis(Cossani and Reynolds, 2012; Ristic et al., 2008). Starch synthesis is highly sensitive to high temperature and drought stress due to the susceptibility of the soluble starch synthase in developing wheat kernels (Keeling et al., 1993; Jenner et al., 1994). Starch accumulation in wheat grains is significantly reduced by over $30 \%$ at temperatures between $30^{\circ} \mathrm{C}$ and $40^{\circ} \mathrm{C}$ (Stone et al., 1995). Identification and deployement of favourable alleles imparting tolerance to heat and drought are crucial to restrict yield losses (Furbank and Tester, 2011). Considerable genetic diversity in wheat germplasm for thermo and drought tolerance has been observed (Lopes et al., 2013, 2014; Sun et al., 2013; Chand et al., 2014; Tadesse et al., 2015). Owing to their genetic diversity, multi-allelic nature, high reproducibility and co-dominant inheritance SSRs are the most preferred markers for genetic diversity, linkage mapping and MAS assisted selection (Jaiswal et al., 2017, Sajjad et al., 2018). These markers have been harnessed extensively for assessment of genetic diversity and molecular genetic mapping of wheat (Abbasov, 2018; Henkrar et al., 2016). Sadat et al. (2013) affirmed use of various SSR markers linked with heat and drought tolerant traits in MAS for screening heat tolerant wheat genotypes. The SSRs used by him were linked with various heat and drought tolerant traits like Heat Susceptibility Index/ single kernel weight of main spike, HSI/grain filling duration and HSI/kernel weight under heat stress in MAS for screening wheat genotypes to heat stress.

Marker assisted selection provides better understanding of the underlying genetic basis of stress tolerance in crops (Liu et al., 2006; Momcilovic and Ristic, 2007). Responsiveness of different heat tolerant genotypes for enzymes like NRA (Nitrate reductase) and Peroxidase along with heat shock proteins is an indicative of thermotolerance. Due to difficulty in phenotype selection and general complexicity of stress tolerance MAS is the most suitable approach to impart stress tolerance.Validating QTLs linked to heat and drought stress in wheat would help to improve breeding efficiency and increase genetic gains (Tadesse et al., 2015). Efforts have been made to improve heat and drought tolerance of wheat through traditional breeding programmes, and studies have utilized molecular characterization and physiological traits for the characterization of genetic diversity (Semenov and Halford, 2009). Conventional wheat lacks the genetic diversity for heat and drought tolerance. Therefore, identification of allelic diversity in wheat germplasm has been a major breeding objective.Identification and characterization of alleles conferring tolerance to combined effect of heat and drought would be beneficial for wheat breeding programmes for the development of high-yielding, stable and heat-drought tolerant genotypes.

\section{Material and methods}

\subsection{Plant material}

The experimental material consisted of 36 diverse wheat cultivars procured from ICAR- Indian Institute of Wheat and Barley Research, Karnal. Seeds were surface sterilized by $0.1 \% \mathrm{HgCl}_{2}$ for $2 \mathrm{~min}$ and were germinated on filter papers in dark room at room temperature. After germination the seedlings were transferred to growth chamber under controlled light and humidity conditions (16 h light, $500 \mu \mathrm{mol}$ fluorescent light, $22.15^{\circ} \mathrm{C}$ day/ night temperature with $60 \%$ humidity). After 8-9 days sufficiently grown leaf samples were harvested for DNA extraction.

\subsection{DNA extraction and PCR amplification}

DNA extraction was performed using CTAB method devised by Doyle and Doyle (1990) with little modifications (Sharma et al., 2014). Approximately $100 \mathrm{mg}$ of leaf samples were crushed in $1.33 \times \mathrm{CTAB}$ buffer and incubated at $65^{\circ} \mathrm{C}$ for $30 \mathrm{~min}$. The quality of DNA was evaluated on $0.8 \%$ agarose gel electrophoresis and quantification was done using nanodrop.

PCR profiling of all the 36 wheat genotypes was done using already reported 24 markers associated with QTL markers for heat and drought (Kumar et al., 2012; Gupta et al., 2017; Jaiswal et al., 2017). PCR reaction was performed in a volume of $20 \mu \mathrm{l}$ containing $1 \mu \mathrm{l}$ of DNA (25 ng), 10 $\mu \mathrm{l}$ of PCR master mix (Thermofisher Green taq), $10 \mu \mathrm{l}$ of both primers $(0.5 \mathrm{\mu l}$ each of $\mathrm{R}$ and $\mathrm{F}$ primer $)$ and 0.025 $\mu \mathrm{l}$ of DNA Polymerase and DNAse free water is added to make up a volume of $20 \mathrm{\mu l}$. PCR programme was run on Gradient thermal cycler S 1000 TM (BioRad). PCR amplification was performed with initial denaturation at $94^{\circ} \mathrm{C}$ for $5 \mathrm{~min}$, followed by 35 cycle of $30 \mathrm{~s}$ at $94^{\circ} \mathrm{C}, 1 \mathrm{~min}$ 
at annealing temperature $55-60^{\circ} \mathrm{C}, 1$ min elongation at $72^{\circ} \mathrm{C}$ and final extension at $72^{\circ} \mathrm{C}$ for $10 \mathrm{~min}$. The amplified PCR products were electrophoresis in $0.5 \times$ TAE buffer at $70 \mathrm{~V}$ on a $2.0 \%$ agarose gel. Gels were stained with ethidium bromide and DNA bands were visualized under UV light using Gel Documentation System (Alpha Imager, Systems and Control). The size of amplification bands was estimated by comparison with a 100-bp standard molecular weight (Merck Chemicals).

\subsection{Data analysis}

Dendrogram was performed using DARWIN (SAS 9.3 NC).The DNA fingerprint patterns obtained were converted into binary data matrices containing arrays of 0 s and 1s. The SSR bands were scored visually for the presence (1) or absence (0) of bands of various mol. wt. sizes. Only polymorphic and reproducible bands were considered for further analysis. The allele number and polymorphic information content (PIC) (Botstein et al. 1980) were calculated using Power marker software (Liu and Muse, 2005).

\section{Results and discussion}

\subsection{Heat tolerance patterns of SSR polymorphism and genetic diversity}

In this study 24 already reported heat and drought (Table 1) were validated on a set of wheat cultivars to characterize the allelic diversity for heat and drought stress. The physiological traits associated with heat tolerance of these wheat cultivars are already reported (Sharma $e t$ al., 2016). The total number of alleles and genetic diversity for heat and drought tolerance were determined for these genotypes and are presented in Table 1. Out of the 24 SSR markers 19 were found polymorphic and rest 5 were found monomorphic. The polymorphic markers were found to be distributed across different wheat chromosomes. The no of alleles for polymorphic SSR markers varied from 2 to 5 with $c f d 43$ and $X b a r c 76$ showing maximum no. of alleles. The PIC values that estimate the discriminating ability of any locus by considering the number of alleles per locus and their relative frequency varied according to markers (Anderson et al., 1993).The mean value of PIC was 0.39 and ranged between 0.02 to 0.65 for the SSR markers Xgwm293 and Xgwm111 respectively. The SSR markers Xgwm471, Xgwm389, Xgwm264, Xgwm146, cfd19, cfd233, Xgrwm111, Xgwm148,Xbarc76 and Xbarc128 were found to possess high polymorphism. These markers revealed the allelic diversity of 36 wheat genotypes for heat and drought stress tolerance. The banding pattern for SSR marker Xgrw 111 decipher considerable genetic variability as shown in Fig 1A. Xgrm 111 yielded 1- 3 alleles and the variation in molecular weight of the bands represent significant allelic diversity for heat and drought stress among these genotypes. Xgwm389 amplified as a single band for most of the genotypes and the amplicon molecular weight varied significantly in certain genotypes suggesting considerable genetic diversity among the tested wheat genotypes (Fig. 1B). Considering polymorphism, the chosen markers are very informative. The marker Xgwm63-7A (PIC = 0.364) and Xgrm 133-6B (PIC = 0.618) have been previously reported to be linked with the QTL for heat tolerance in wheat (Mohammadi et al.,2008). Our results corroborate findings of (Sharma et al., 2016; Sharma et al., 2014; Bousba et al., 2012; Khanjari et al., 2007). Rai et al.(2017) also validated SSR markers linked with drought and heat QTLs in bread wheat and found that six SSR markers were appropriate for selection of drought and heat tolerant lines for use in marker assisted backcross breeding programs.Therefore, these markers could be exploited in wheat breeding programme for heat and drought tolerance and the wheat genotypes thus identified to be genetically diverse at allelic level can be exploited in breeding programs.

\subsection{Cluster analysis of marker based data}

Cluster analysis was carried out to classify the 36 wheat cultivars for genetic variation in heat tolerance. The dendrogram constructed using SSR markers data assigned the wheat cultivars into three clusters (Fig.2). Cluster I consisted of twelve genotypes (GW322, MACS2496, NIAW34, VL616, PBW550, UP2338, HD2687, WH1080, RAJ4083, WH730, PBW343, DBW 17). Cluster II consisted 17 cultivars (RAJ4079, RAJ4037, RAJ4210, WR544, MP4010, K7903, NI5439, MACS6145, HI1500, HUW510, HD2808, C306, WH147, UP2382, DBW14, DBW90, CBW38), while Cluster III had seven genotypes (PBW590, HD2967, HUW468, HD2932, HS240, NW1014, RAJ3765). Paudel et al. (2019) in a similar study determined genetic diversity of wheat genotypes for heat and drought tolerance using SSR markers and clustered 20 wheat genotypes into 5 major clusters. In present study the heat tolerant genotypes clustered in different groups 
Table 1: SSR markers that were found polymorphic for heat and drought tolerance

\begin{tabular}{|c|c|c|c|c|c|}
\hline Sl. No. & Marker & Primer sequence & $\begin{array}{l}\text { Chromosomal } \\
\text { location }\end{array}$ & No of allele & PIC \\
\hline 1 & Xgwm66 & $\begin{array}{l}\text { F 5'CCAAAGACTGCCATCTTTCA 3', } \\
\text { R 5'CATGACTAGCTAGGGTGTGACA 3' }\end{array}$ & $4 \mathrm{~B}$ & 2 & 0.46875 \\
\hline 2 & Xgwm95 & $\begin{array}{l}\text { F 5'GATCAAACACACACCCCTCC 3', } \\
\text { R 5'AATGCAAAGTGAAAAACCCG 3' }\end{array}$ & $2 \mathrm{~A}$ & 2 & 0.496327 \\
\hline 3 & Xgwm99 & $\begin{array}{l}\text { 5'AAGATGGACGTATGCATCACA 3' } \\
\text { 5' GCCATATTTGATGACGCATA 3' }\end{array}$ & - & 2 & 0.498457 \\
\hline 4 & Xgwm337 & $\begin{array}{l}\text { 5'CCTCTTCCTCCCTCACTTAGC 3' } \\
\text { 5' TGCTAACTGGCCTTTGCC 3' }\end{array}$ & $1 \mathrm{~B}, 1 \mathrm{D}$ & 2 & 0.499314 \\
\hline 5 & Xgwm493 & $\begin{array}{l}\text { F 5'TTCCCATAACTAAAACCGCG 3' } \\
\text { R 5'GGAACATCATTTCTGGACTTTG 3' }\end{array}$ & $3 \mathrm{~B}$ & 3 & 0.634259 \\
\hline 6 & Xgrem495 & $\begin{array}{l}\text { F 5'GAGAGCCTCGCGAAATATAGG 3' } \\
\text { R 5'TGCTTCTGGTGTTCCTTCG 3' }\end{array}$ & $4 \mathrm{~B}$ & 3 & 0.368827 \\
\hline 7 & Xgwm389 & $\begin{array}{l}\text { F 5' ATCATGTCGATCTCCTTGACG 3' } \\
\text { R 5' TGCCATGCACATTAGCAGAT 3' }\end{array}$ & $3 \mathrm{~B}$ & 2 & 0.165123 \\
\hline 8 & Xgwm264 & $\begin{array}{l}\text { F 5'GAGAAACATGCCGAACAACA 3' } \\
\text { R 5'GCATGCATGAGAATAGGAACTG 3' }\end{array}$ & $3 \mathrm{~B}$ & 2 & 0.413194 \\
\hline 9 & Xgwm471 & $\begin{array}{l}\text { F 5'CGGCCCTATCATGGCTG 3' } \\
\text { R 5'GCTTGCAAGTTCCATTTTGC 3' }\end{array}$ & $7 \mathrm{~A}$ & 3 & 0.373016 \\
\hline 10 & Xgwm146 & $\begin{array}{l}\text { F 5'CCAAAAAAACTGCCTGCATG 3' } \\
\text { R 5'CTCTGGCATTGCTCCTTGG 3' }\end{array}$ & $7 \mathrm{~B}$ & 2 & 0.202449 \\
\hline 11 & Xgwm148 & $\begin{array}{l}\text { F 5'GTGAGGCAGCAAGAGAGAAA 3', } \\
\text { R 5'CAAAGCTTGACTCAGACCAAA 3' }\end{array}$ & $2 \mathrm{~B}$ & 3 & 0.414201 \\
\hline 12 & Xgrwm293 & $\begin{array}{l}\text { F 5'TACTGGTTCACATTGGTGCG 3' } \\
\text { R 5'TCGCCATCACTCGTTCAAG 3' }\end{array}$ & $5 \mathrm{~A}$ & 2 & 0.057093 \\
\hline 13 & Xgwm111 & $\begin{array}{l}\text { F 5' TCTGTAGGCTCTCTCCGACTG 3' } \\
\text { R 5' ACCTGATCAGATCCCACTCG 3' }\end{array}$ & $7 \mathrm{~B}, 7 \mathrm{D}$ & 4 & 0.716441 \\
\hline 14 & Xbarc76 & $\begin{array}{l}\text { F 5' ATTCGTTGCTGCCACTTGCTG 3' } \\
\text { R 5' GCGCGACACGGAGTAAGGACACC 3' }\end{array}$ & $2 \mathrm{~A}, 6 \mathrm{~B}, 7 \mathrm{D}$ & 5 & 0.670976 \\
\hline 15 & Xbarc186 & $\begin{array}{l}\text { F 5'CGCTTCCCATAACGCCGATAGTAA } \\
\text { R 3' 5'CGCCCGCATCATGAGCAATTCTATCC 3' }\end{array}$ & $5 \mathrm{~A}$ & 4 & 0.599184 \\
\hline 16 & $c f d 43$ & $\begin{array}{l}\text { F 5' AACAAAAGTCGGTGCAGTCC 3' } \\
\text { R 5' CCAAAAACATGGTTAAAGGGG 3' }\end{array}$ & $2 \mathrm{D}$ & 5 & 0.768833 \\
\hline 17 & wmc273 & $\begin{array}{l}\text { F 5'AGTTATGTATTCTCTCGAGCCTG 3', } \\
\text { R 5'GGTAACCACTAGAGTATGTCCTT 3' }\end{array}$ & $7 \mathrm{~A}$ & 4 & 0.6218 \\
\hline 18 & wmc455 & $\begin{array}{l}\text { F 5'GCGTCATTTCCTCAAACACATC 3' } \\
\text { R 5'AGAAGGAGAAGTGCCTCACCAA 3' }\end{array}$ & $2 \mathrm{~A}$ & 2 & 0.3698 \\
\hline 19 & wmc 473 & $\begin{array}{l}\text { F 5'TCTGTTGCGCGAAACAGAATAG 3', } \\
\text { R 5'CCCATTGGACAACACTTTCACC 3' }\end{array}$ & $4 \mathrm{D}$ & 2 & 0.3415 \\
\hline 20 & wmc11 & $\begin{array}{l}\text { F 5'TTGTGATCCTGGTTGTGTTGTGA 3', } \\
\text { R 5'CACCCAGCCGTTATATATGTTGA 3' }\end{array}$ & $3 \mathrm{~A}$ & 4 & 0.6445 \\
\hline 21 & wmc181 & $\begin{array}{l}\text { F 5'TCCTTGACCCCTTGCACTAACT 3', } \\
\text { R 5'ATGGTTGGGAGCACTAGCTTGG 3' }\end{array}$ & $2 \mathrm{~A}$ & 4 & 0.5752 \\
\hline 22 & wmc364 & $\begin{array}{l}\text { F 5'ATCACAATGCTGGCCCTAAAAC 3', } \\
\text { R 5'CAGTGCCAAAATGTCGAAAGTC 3' }\end{array}$ & $7 \mathrm{~B}$ & 3 & 0.4768 \\
\hline 23 & cfd19 & $\begin{array}{l}\text { F 5' TACGCAGGTTTGCTGCTTCT 3' } \\
\text { R 5 ' GGAGTTCACAAGCATGGGTT 3' }\end{array}$ & $1 \mathrm{D}$ & 4 & 0.3877 \\
\hline 24 & $c f d 233$ & $\begin{array}{l}\text { F 5' GAATTTTTGGTGGCCTGTGT 3' } \\
\text { R 5' ATCACTGCACCGACTTTTGG 3' }\end{array}$ & $2 \mathrm{D}$ & 2 & 0.2642 \\
\hline
\end{tabular}

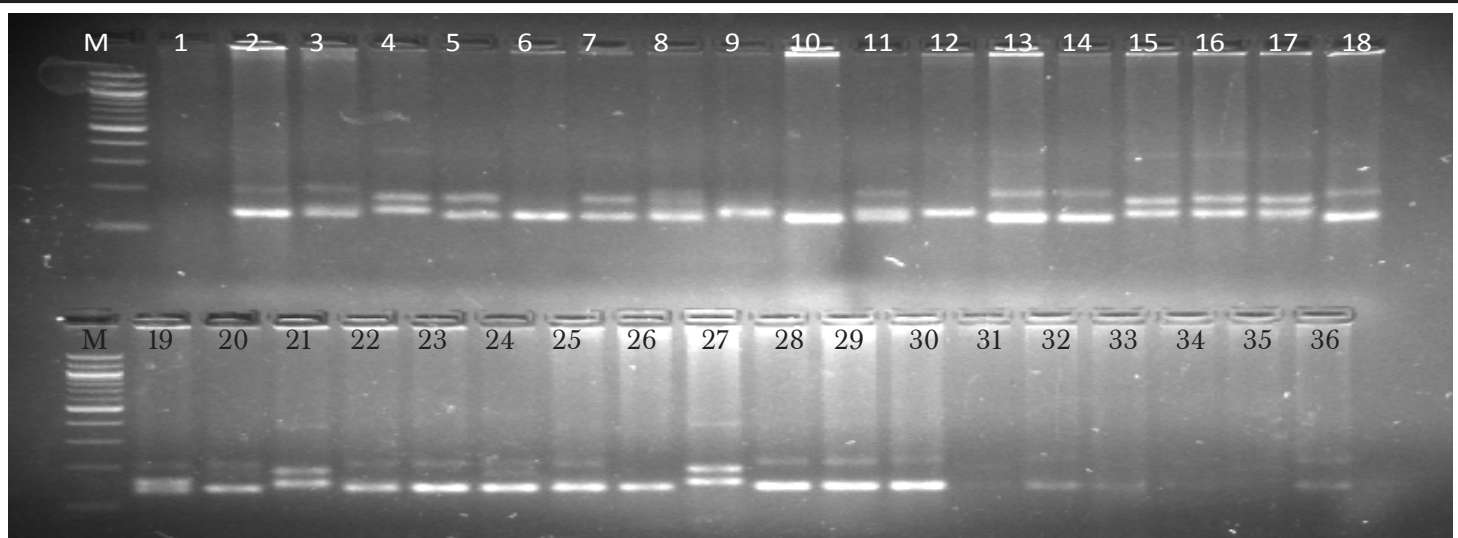

Fig1A: Gel showing amplification of Xgwm111, Number of alleles ranged from 1-3 with molecular weight in a range of 140-200 


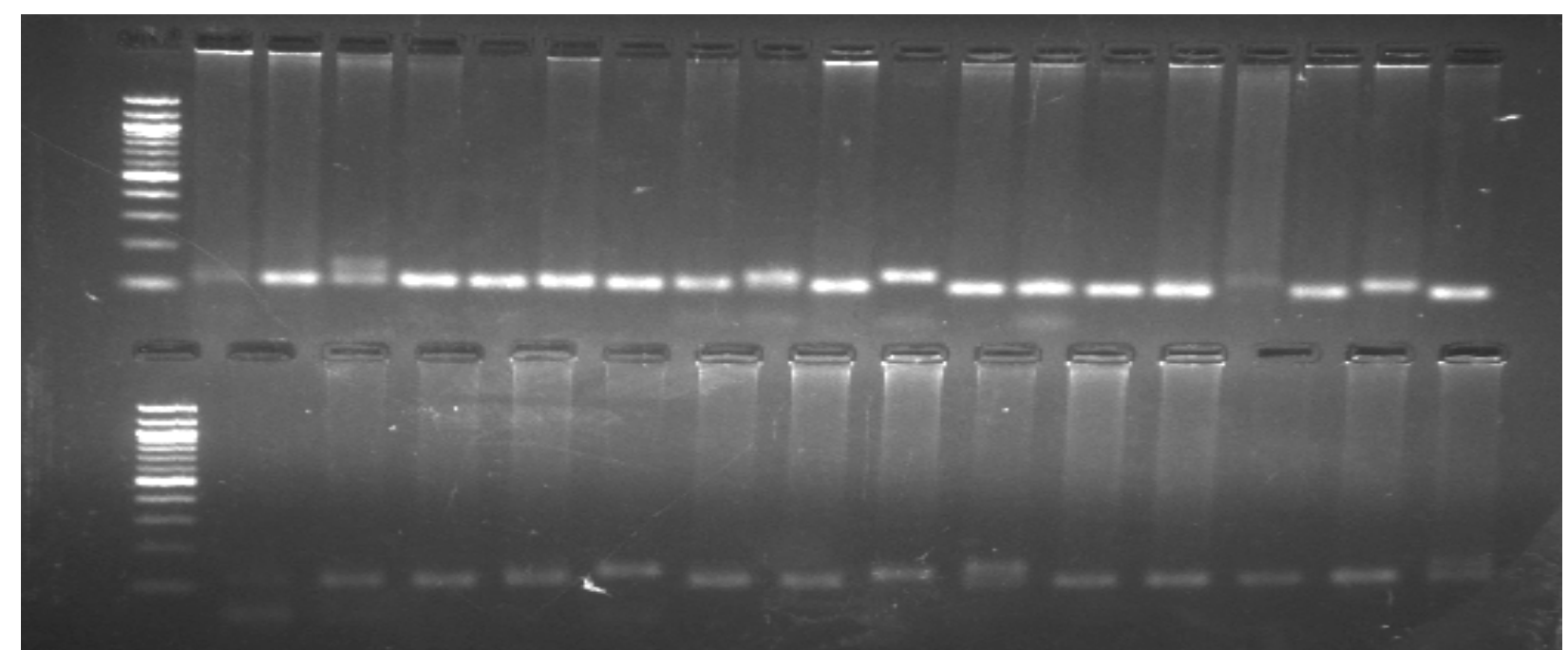

Fig1B: Gel showing amplification of Xgwm389,number of alleles ranged from 1-2 with molecular weight in a range of 110-130

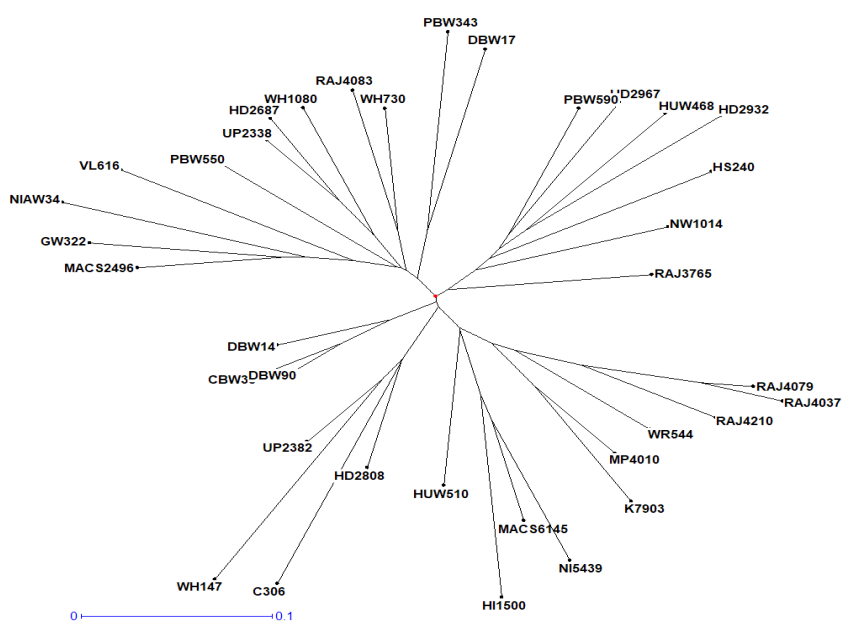

Fig. 2: UPGMA dendrogram based on genetic variation for heat and drought stress tolerance obtained through STRUCTURE analysis

highlighting different genetic basis of tolerance in various genotypes. Bhusal et al. (2017) also mapped 24 QTLs for grain yield components in wheat under heat stress in cultivar HD2808.

\section{Conclusion}

Genetic diversity among thirty-six wheat genotypes was

\section{References}

1. Abbasov M, Z Akparov, T Gross, S Babayeva, V Izzatullayeva, E Hajiyev, K Rustamov, P Gross, M Tekin, T Akar, S Chao and R Brueggeman. 2016. Genetic relationship of diploid wheat (Triticum spp.) species assessed by SSR markers. Genetic Resources and Crop Evolution 65(5): 1441-1453. assessed using already reported SSR markers. Genetically diverse heat and drought tolerant wheat genotypes thus identified provides the great potential to breed heat and drought tolerant wheat varieties. This information will be useful to identify new source of tolerance for breeding programme for improved wheat varieties capable of facing the environmental challenges.

2. Alexander LV, X Zhang, TC Peterson, J Caesar, B Gleason, AM KleinTank, M Haylock, D Collins, B Trewin, F Rahimzadeh and A Tagipour. 2006. Global observed changes in daily climate extremes of temperature and precipitation. Journal of Geophysical Research: Atmospheres 111(D5). 
3. Anderson JA, GA Churchill, JE Autrique, SD Tanksley and ME Sorrells. 1993. Optimizing parental selection for genetic linkage maps. Genome 36: 181-186.

4. Asseng S, F Ewert, P Martre, RP Rötter, DB Lobell, D Cammarano, et al. 2015. Rising temperatures reduce global wheat production. National Climatic Change 5: 143-147.

5. Bhusal N, AK Sarial, P Sharma and S Sareen. 2017. Mapping QTLs for grain yield components in wheat under heat stress. PLoS ONE 12(12): e0189594.

6. Botstein D, RL White, M Skolnick and RW Davis. 1980. Construction of a genetic linkage map in man using restriction fragment length polymorphisms. The American Journal of Human Genetics 32: 314-331.

7. Bousba R, M Baum, A Djekoune, S Labadidi, A Djighly, K Benbelkacem, M Labhilili, F Gaboun, N Ykhlef. 2012. Screening for drought tolerance using molecular markers and phenotypic diversity in durum wheat genotypes. World Applied Sciences Journal 16(9): 1219-1226.

8. Chand U, A Bohra and NP Singh. 2014. Heat stress in crop plants: Its nature, impacts, and integrated breeding strategies to improve heat tolerance. Plant Breeding 133: 679-701.

9. Cossani CM and MP Reynolds. 2012. Physiological traits for improving heat tolerance in wheat. Plant Physiology 160: 1710-1718.

10. Doyle JJ and JL Doyle. 1990. Isolation of plant DNA from fresh tissue. Focus 12: 13-15.

11. FAO 2019. World food situation. Available at: http:// www.fao.org/worldfoodsituation/csdb/en/(Accessed May 26, 2019).

12. FAO. 2018. FAOSTAT. FAO, Rome, Italy. http:// faostat.fao.org.

13. Furbank RT and M Tester. 2011. Phenomicstechnologies to relieve the phenotyping bottleneck. Trends Plant Sciences 16: 635-644.

14. Gaffen DJ and RJ Ross. 1998. Increased summer time heat stress in the US. Nature 396(6711): 529-530.
15. Gbegbelegbe S, D Cammarano, S Asseng, R Robertson, U Chung, M Adam et al. 2016. Baseline simulation for global wheat production with CIMMYT mega-environment specific cultivars. Field Crops Resources 202: 122-135.

16. Henkrar F, J El-Haddoury, H Ouabbou, N Nsarellah, D Iraqi, N Bendaou and SM Udupa. 2016. Genetic diversity reduction in improved durum wheat cultivars of Morocco as revealed by microsatellite markers. Science Agriculture 73(2): 134-141.

17. Hennessy K, R Fawcett, D Kirono, F Mpelasoka, D Jones, J Bathols, P Whetton, SM Smith, M Howden, C Mitchell and N Plummer. 2008. An assessment of the impact of climate change on the nature and frequency of exceptional climatic events. Australian Government Bureau of Meteorology: Melbourne.

18. Izanloo A, AG Condon, $\mathrm{P}$ Langridge, $\mathrm{M}$ Tester and T Schnurbusch. 2008. Different mechanisms of adaptation to cyclic water stress in two South Australian bread wheat cultivars. Journal of Experimental Botany 59: 3327-3346.

19. Jaiswal S, S Sheoran, V Arora, UB Angadi, MA Iquebal, N Raghav, B Aneja, D Kumar, R Singh, P Sharma, GP Singh, A Rai, R Tiwari and D Kumar. 2017. Putative microsatellite DNA marker-based wheat genomic resource for varietal improvement and management. Frontiers in Plant Sciences 8: 2009.

20. Jenner CF. 1994. Starch synthesis in the kernel of wheat under high temperature conditions. Functional Plant Biology 21: 791-806.

21. Keeling PL, PJ Bacon and DC Holt. 1993. Elevated temperature reduces starch deposition in wheat endosperm by reducing the activity of soluble starch synthase. Planta 191: 342-348.

22. Khanjari SA, KH Ammer, A Buerkert and Röder MS. 2007. Molecular diversity of Omani wheat revealed by microsatellites: II. Hexaploid landraces. Genetic Resources and Crop Evolution 54: 1407-1417.

23. Kumar S, SK Shegal, U Kumar, B Gill. 2012. Genomic characterization of drought tolerance-related traits in spring wheat. Euphytica 186 (1):265-276 
24. Kumar S, G Singroha, SC Bhardwaj, R Bala, MS Saharan et al. 2019. Multienvironmental evaluation of wheat (Triticum aestivum) germplasm identifies donors with multiple fungal diseases resistance. Genetic Resources and Crop Evolution 66: 797-808.

25. Liu HT, F Gao, SJ Cui, JL Han, DY Sun and RG Zhou. 2006. Primary evidence for involvement of IP3 in heat-shock signal transduction in Arabidopsis. Cell Research 16(4): 394-400.

26. Liu K and SV Muse. 2005. Power marker: an integrated analysis environment for genetic marker analysis. Bioinformatics 21: 2128-2129.

27. Lobell DB, A Sibley and JI Ortiz-Monasterio. 2012. Extreme heat effects on wheat senescence in India. National Climatic Change 2: 186.

28. Mohammadi V, AA Zali and MR Bihamta. 2008. Mapping QTL for heat tolerance in wheat. Journal of Agricultural Sciences and Technology 10: 261-267.

29. Momcilovic I and Z Ristic. 2007. Expression of chloroplast protein synthesis elongation factor, EF-Tu, in two lines of maize with contrasting tolerance to heat stress during early stages of plant development. Journal of Plant Physiology 164(1): 90-99.

30. Ortiz R, KD Sayre, B Govaerts, R Gupta, GV Subbarao, T Ban et al. 2008. Climate change: Can wheat beat the heat? Agric. Ecosystem and Environment 126: $46-58$.

31. Pandey GC, Geetika, Sharma P and Sharma V. 2019. Terminal heat tolerance in wheat: an overview. Journal of Cereal Research 11(1): 1-16

32. Poudel MR, SK Ghimire, MP Pandey, KH Dhakal, DB Thapa and DK Khadka. 2019. Assessing genetic diversity for drought and heat stress tolerance of Nepalese wheat genotypes by SSR markers. Eurasia Journal of Biosciences 13: 941-948.

33. Rai N, B Amasiddha, N Jain, GP Singh, PK Singh, S Chand and KV Prabhu. 2017. Validation of SSR markers linked with drought and heat tolerant QTLs in bread wheat (Triticum aestivum L. em.Thell.). International Journal of Pure and Applied Biosciences 5(5): 700-705.
34. Ristic Z, U Bukovnik, I Mom ilovi, JM Fu and PVV Prasad. 2008. Heat-induced accumulation of chloroplast protein synthesis elongation factor, EF-Tu, in winter wheat. Australian Journal of Plant Physiology 165: 192-202.

35. Sadat S, KA Saeid, MR Bihamta, S Torabi, SGH Salekdeh and GAL Ayeneh. 2013. Marker assisted selection for heat tolerance in bread wheat. World Applied Sciences Journal 21(8): 1181-1189.

36. Sajjad M, SH Khan and M Shahza. 2018. Patterns of allelic diversity in spring wheat populations by SSRmarkers. Cytology Genetics 52: 155-160.

37. Schillinger WF, SE Schofstoll and JR Alldredge. 2008. Available water and wheat grain yield relations in a Mediterranean climate. Field Crops Research 109: 45-49.

38. Semenov MA and NG Halford. 2009. Identifying target traits and molecular mechanisms for wheat breeding under a changing climate. Journal of Experimental Botany 60: 2791-2804.

39. Senapati N, P Stratonovitch, MJ Paul and MA Semenov. 2019. Drought tolerance during reproductive development is important for increasing wheat yield potential under climate change. European Journal of Experimental Botany 70(9): 2549-2560.

40. Sharma P, M Saini, S Sareen and I Sharma. 2016. Assessing genetic variation for heat stress tolerance in Indian bread wheat genotypes using morphophysiological traits and molecular markers. Plant Genetic Resources 15(6): 539-547.

41. Sharma P, M Saini, S Sareen, A Verma, BS Tyagi and I Sharma. 2014. Assessing genetic variation for heat tolerance in synthetic wheat lines using phenotypic data and molecular markers. Australian Journal of Crop Sciences 8(4): 515-522.

42. Slafer GA and EH Satorre. 1999. Wheat: Ecology and Physiology of Yield Determination. Haworth Press Technology and Industrial, ISBN 1560228741.

43. Stone PJ and ME Nicolas. 1995. Effect of timing of heat stress during grain filling on two wheat varieties differing in heat tolerance on grain growth. Australian Journal of Plant Physiology 22: 927-934. 
44. Sun J, H Luo, J Fu and B Huang. 2013. Classification of genetic variation for drought tolerance in tall fescue using physiological traits and molecular markers. Crop Science 53: 647-654.

45. Tadesse W, FC Ogbonnaya, A Jighly, M SanchezGarcia, Q Sohail, S Rajaram and M Baum. 2015. Genome-wide association mapping of yield and grain quality traits in elite winter wheat genotypes. PLoS One 10:e141339.

46. Talukder S, M Babar, K Vijayalakshmi, J Poland, P Prasad, R Bowden and A Fritz. 2014. Mapping QTL for the traits associated with heat tolerance in wheat (Triticum aestivum L.) Z. BMC Genetics 15: 97.

47. Toreti A, O Cronie and M Zampieri. 2019. Concurrent climate extremes in the key wheat producing regions of the world. Scientific Reports 9: 5493.

48. Wollenweber B, JR Porter and J Schellberg. 2003. Lack of interaction between extreme high temperature events at vegetative and reproductive growth stages in wheat. Journal of Agronomy and Crop Science 189(3): 142-150. 